\title{
Is there any relationship between RDW levels and atrial fibrillation in hypertensive patient?
}

\author{
${ }^{1}$ Savas Sarıkaya, ${ }^{2} S ̧ a f a k$ Şahin, ${ }^{3}$ Lütfi Akyol, ${ }^{3}$ Elif Börekçi, ${ }^{4}$ Yunus Keser Yılmaz, \\ ${ }^{5}$ Fatih Altunkaş, ${ }^{5}$ Kayıhan Karaman
}

1. Department of Cardiology, Bozok university, Yozgat Turkey

2. Department of Internal Medicine, Gaziosmanpaşa university, Tokat Turkey

3. Department of internal medicine, Bozok university, Yozgat Turkey

4. Department of cardiovascular surgery, Bozok university, Yozgat Turkey

5. Department of Cardiology, Gaziosmanpaşa university, Tokat Turkey

\begin{abstract}
Background: Atrial fibrillation (AF) is the most common cardiac arrhythmia and increases the risk of stroke and death. Patients with hypertensive have an increased risk of developing atrial fibrillation. RDW (Red blood cell distribution width) levels are elevated in cardiovascular disorders including heart failure, stable coronary disease, acute coronary syndrome, slow coronary flow and stroke.
\end{abstract}

Objective: We aimed to investigate the relation between RDW and AF in patients with hypertensive Method: We retrospectively examined 126 consecutive hypertensive patients (63 hypertensive patients with AF and 63 hypertensive patients without AF matched with age and sex

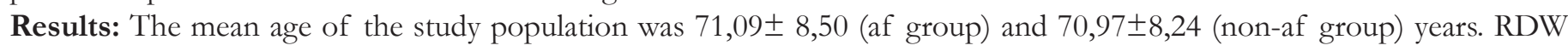
level was different among patients with atrial fibrillation and without atrial fibrillation.(15,13 $\pm 1,58$ and $14,05 \pm 1,15 \mathrm{p}<001)$. Logistic regression analysis showed that RDW and left atrial dimension were only independently risk factory associated with atrial fibrillation. (Rdw odds ratio:1,846 CI; 1,221-2,793 p<0,05). Roc curve analyses were applied to determine the cut-off point. Cut-off point was at 14,195 and Sensitive, specificity was \%71,4, \%56 respectively.

Conclusion: RDW levels were higher in hypertensive patients with atrial fibrillation. An increased RDW level in the patient with hypertension may alert physician on developing or presence of atrial fibrillation.

Keywords: atrial fibrillation, red blood cell distribution width, hypertension.

African Health Sciences 2014;14(1): 267-272 http://dx.doi.org/10.4314/ahs.v14i1.41

\section{Introduction}

Atrial fibrillation (AF) is the most common cardiac arrhythmia and increases the risk of stroke and death. Several atherosclerotic risk factors, such as obesity, diabetes and hypertension, are associated with development of AF. (1-3) Many studies have shown that individuals with hypertension have an increased risk of developing atrial fibrillation compared with normotensive individuals.(4-6) Several inflammatory markers such as C-reactive protein (CRP), tumor necrosis factor- $\alpha(\mathrm{TNF}-\alpha)$, interleukin (IL)-2, IL-6, IL-8, and monocyte chemo attractant protein

\section{Correspondence: \\ Savaş Sarikaya MD \\ Department of Cardiology \\ Bozok university, Yozgat Turkey \\ Phone: +903546070 \\ Fax: +903546070 \\ E-mail: cardiology58@gmail.com}

(MCP)-1 and mediators have been shown associated with the presence or the outcome of AF.(7) A growing body of literature supports a role for the immune system and chronic inflammation in the development of hypertension. (8; 9) Red blood cell distribution width (RDW) is a measurement of the variability in size of circulating erythrocytes. RDW is obtained routinely in standard complete blood cell counts (CBCs). Increased RDW indicates the presence of anisocytosis, which is related to impaired erythropoiesis and erythrocyte degradation, reflecting chronic inflammation and a high level of oxidative stress.(10-12) Recent studies have reported that RDW levels are elevated in cardiovascular disorders including heart failure, stable coronary disease, acute coronary syndrome, slow coronary flow and in non-cardiovascular diseases, stroke.(13-17)

However, to the best of our knowledge, to evaluate the relation between RDW and AF in patients with hypertensive has not been reported in the literature previously. In this study, we aimed to investigate the relation between RDW and AF in patients with hypertensive 


\section{Method}

Patient selection

We retrospectively examined 126 consecutive hypertensive patients (63 hypertensive patients with $\mathrm{AF}$ and 63 hypertensive patients without AF matched with age and sex) at university of Bozok and GOP. All patients' records of history and physical examinations were examined in detail. No patient had a recent history of an acute infection or an inflammatory disease. Patients with renal failure, concomitant valvular disease, cardiomyopathy, and previous cardiac surgery and seconder hypertension were excluded.

\section{Echocardiographic assessment}

Transthoracic 2-dimensional and Doppler echocardiographic assessment was performed. (Aloca, Japon). Measurements of the left atrium, left ventricle and right ventricle was obtained from parasternal long axis view according to standard criteria. Left ventricular ejection fraction (LVEF) was calculated using the modified Simpson's rule in the 2- and 4-chamber apical views.

\section{Measurement of laboratory parameters}

On admission, venous bloods were obtained from the antecubital vein from all patients after fasting for at least 8 h. Fasting plasma glucose (FBG), creatinine, plasma levels of total cholesterol (TC), low-density lipoprotein (LDL), high-density lipoprotein (HDL) cholesterol and triglyceride (TG) were determined by a hospital auto analyzer. CBC analysis including RDW was performed with Beckman Coulter LH 750 automated analyzer

within $2 \mathrm{~h}$.

\section{Statistic}

The statistical analyses were performed using software (SPSS 18.0). Parametric values were given as mean \pm standard deviation and non-parametric values were given as a percentage. To compare parametric continuous variables, Student's t-test was used; to compare nonparametric continuous variables, the Mann-Whitney U-test was used. Categorical data were compared by Chi-square distribution. Receiver operator characteristic (ROC) curve analysis was performed to identify the optimal cut-off point of RDW (at which sensitivity and specificity would be maximal) for the prediction of AF. Areas under the curve (AUC) were calculated as measures of the accuracy of the tests. We compared the AUC with the use of the Z test. Variables found to be statistically significant in univariate analyses were entered into multivariate logistic regression analysis .Multivariate logistic regression models were created to identify independent predictors of AF. Two-tailed P-values of less than 0.05 were considered to indicate statistical significance.

\section{Results}

There were no significant differences among patients with or without atrial fibrillation in terms of gender, age, coronary artery disease, diabetes Mellitus. The mean age of the study population was $71,09 \pm 8,50$ (af

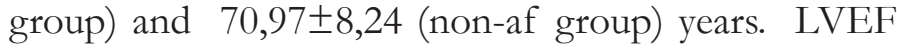
and left atrium dimensions (LAD) TG,TC,and RDW levels were different between the two groups (Table 1).

Table 2. Multivariate regression analyses

Table 2: Independent predictors of atrial fibrillation in multivariate logistic regression analysis

\begin{tabular}{|l|l|l|l|}
\hline & Odds ratio & CI & P value \\
\hline RDW & 1,846 & $1,221-2,793$ & 0,004 \\
\hline EF & 0,914 & $0,835-1,004$ & 0,06 \\
\hline LAD & 6,985 & $2,451-19,904$ & 0,001 \\
\hline TC & 0,992 & $0,982-1,002$ & 0,137 \\
\hline TG & 1,000 & $0,993-1,006$ & 0,904 \\
\hline
\end{tabular}

RDW: Red Blood Cell Distribution Width EF: Ejection Fraction LAD: Left Atrial Diameter TC: Total Cholesterol TG: Triglyceride 
Table 1. Baseline characteristics of patients

\begin{tabular}{|l|l|l|l|}
\hline Groups & $\begin{array}{l}\mathrm{HT}(+) \mathrm{AF}(+) \\
\mathrm{N}: 63\end{array}$ & $\begin{array}{l}\mathrm{HT}(+) \mathrm{AF}(-) \\
\mathrm{N}: 63\end{array}$ & P value \\
\hline Age & $71,09 \pm 8,50$ & $70,97 \pm 8,24$ & 0,944 \\
\hline Sex(woman)\% & 52,2 & 47,8 & 0,360 \\
\hline DM $\%$ & 36,5 & 39,5 & 0,283 \\
\hline CAD $\%$ & 22,2 & 33,3 & 0,232 \\
\hline Glucose & $108,178 \pm 29,354$ & $112,05 \pm 33,80$ & 0,855 \\
\hline Creatinin & $1,16 \pm 1,21$ & $0,90 \pm 0,23$ & 0,314 \\
\hline TG & $115,03 \pm 70,97$ & $154,05 \pm 105,68$ & 0,023 \\
\hline TC & $170,26 \pm 46,13$ & $214,81 \pm 80,86$ & 0,002 \\
\hline HDL & $42,85 \pm 8,26$ & $44,83 \pm 16,75$ & 0,140 \\
\hline LDL & $106,11 \pm 31,91$ & $123,94 \pm 43,28$ & 0,28 \\
\hline RDW & $15,13 \pm 1,58$ & $14,05 \pm 1,157$ & 0,001 \\
\hline HB & $13,74 \pm 1,38$ & $13,88 \pm 1,62$ & 0,323 \\
\hline EF\% & $52,68 \pm 8,20$ & $57,98 \pm 4,84$ & 0,001 \\
\hline LAD & $4,43 \pm 0,78$ & $3,8 \pm 0,27$ & 0,001 \\
\hline
\end{tabular}

Dm:diabetes mellitus CAD:coronary artery disease TG:Triglyceride TC:Total cholesterol HDL:High Density Cholesterol LDL:Low Density Cholesterol RDW: Red Blood Cell Distribution Wide Hb:Hemoglobin EF:Ejection fraction LAD: Left Atrial Diameter

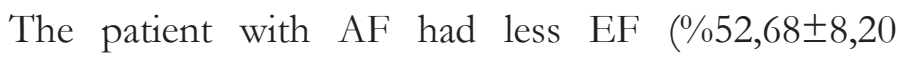
and $57,98 \pm 4,84 \mathrm{p}<0,05)$ and $\operatorname{LAD}(4,43 \pm 0,78$ and $3,8 \pm 0,27 \mathrm{p}<0,05)$ than non-atrial fibrillation group. TC $(170,26 \pm 46,13$ and $214,81 \pm 80,86 \mathrm{p}<0,05), \mathrm{TG}($ $115,03 \pm 70,97$ and $154,05 \pm 105,68 \mathrm{p}<0,05)$ and $\mathrm{Hb}$ $(13,23 \pm 1,32$ and $13,67 \pm 1,79 \mathrm{p}<0,05)$ were different between patients with or without atrial fibrillation respectively. (Table 1) RDW level was different among patients with atrial fibrillation and without atrial fibrillation. $(15,13 \pm 1,58$ and $14,05 \pm 1,15 \mathrm{p}<001)$ (table 1). Variables found to be statistically significant in univariate analyses were entered into multivariate logistic regression analysis.multivariate Logistic regression analysis showed that RDW and left atrial dimension were only independently risk factory associated with atrial fibrillation. (Rdw odds ratio:1,846 CI; 1,221-2,793 $\mathrm{p}<0,05)$ (table 2). 
Roc curve analyses were applied to determine the cut-off point.(Figure 1) Cut-off point was at 14,195 and Sensitive, specificity was $\% 71,4, \% 56$ respectively.

Figure 1. ROC curve analysis of RDW

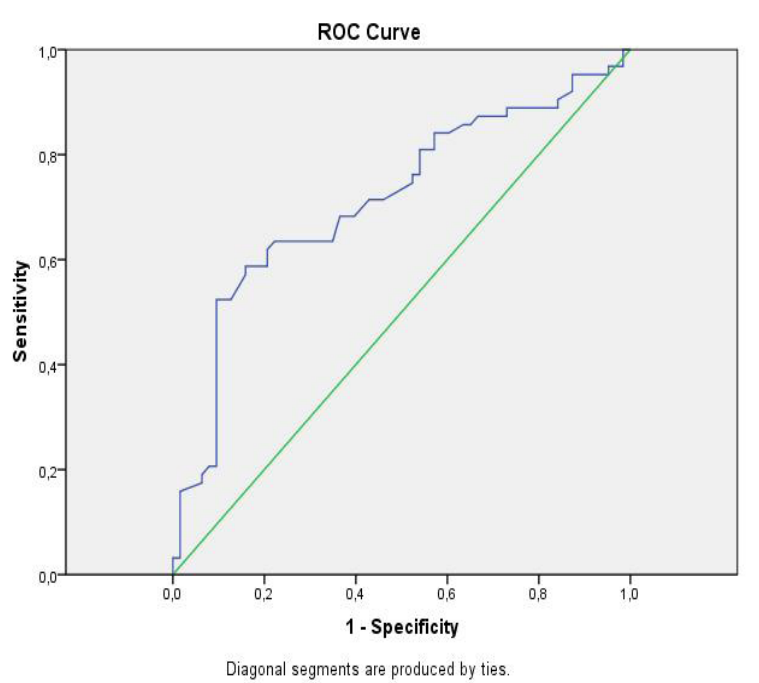

\section{Discussion}

Our study showed that an increased RDW level was independently associated with atrial fibrillation in the patient with hypertension. The cut of point of 14,195 levels was a strong predictor of atrial fibrillation in the patient with hypertension. The sensitive, specificity was $\% 71,4$ and $\% 56$ respectively.

Many studies have shown that individuals with hypertension have an increased risk of developing atrial fibrillation compared with normotensive individuals. (4-6) Elevated systolic blood pressure is associated with increases in left atrial fibrosis, $(18 ; 19)$ which in turn is related to prevalent atrial fibrillation. (20) Some studies suggest that left ventricular hypertrophy and increases in left atrial size may also mediate the relationship between blood pressure and incident atrial fibrillation. $(21 ; 22)$

In our study, LAD was higher in patient with hypertensive patients with AF that those without AF. Anatomic evidence of inflammation ,such as myocyte necrosis, inflammatory infiltrates and fibrosis have been shown in the atrial wall in biopsies of patient with persistent. (23) Several inflammatory markers such as CRP,TNF- $\alpha$ ,IL-2, IL-6, IL-8, and MCP-1 and mediators have been shown associated with the presence or the outcome of AF. (7) Patients with high baseline CRP levels are at higher risk of having postoperative atrial fibrillation in both on-pump and off-pump surgery.(24)
RDW is a numerical measure of the size variability of circulating erythrocytes and is routinely reported as a component of complete blood count in the differential diagnosis of anemia Studies recently have shown that RDW was strong and independent predictor of poor outcome in the general population.(25) RDW has been recently reported that being predictive of poor outcome in several cardiovascular disease including heart failure, stable coronary artery disease and acute myocardial infarction. $(7 ; 15 ; 26 ; 27)$ The mechanism of elevated RDW values are unknown that why it is linked with adverse outcomes. Some studies has been suggested that RDW may reflect prognostic markers in heart failure, such as inflammatory cytokines that may affect bone marrow function and iron metabolism.(28; 29) Agarwal and at all. have demonstrated that subjects with low cardiorespiratory fitness have elevated RDW by virtue of chronic inflammation and high oxidative stress, which is likely to promote atherosclerosis and lead to cardiovascular disease.(19)

A growing body of literature supports a role for the immune system and chronic inflammation in the development of hypertension. $(8 ; 9)$ Higher RDW values were strongly correlated with higher systolic and diastolic blood pressures.(30) RDW was significantly increased in patients with non-dipper hypertension compared with the dipper hypertension. Inflammatory activity 
was closely related to RDW in non-dipper hypertensive patient.(31) In present study, Increased RDW, as a surrogate marker of inflammation, was associated with atrial fibrillation in the patient with hypertensive.

Inflammatory activity is increased in the patient with hypertension. Also, inflammatory activity plays a major role in the presence and developing of atrial fibrillation. RDW is newinflammatorymarker. Therefore, developing of atrial fibrillation in the patient with hypertension may not only associated with diastolic dysfunction also may be related to inflammation but why RDW is increased in the patient with atrial fibrillation with hypertensive is not clear.

However, best of our knowledge to evaluate the relation between RDW and AF in patients with hypertensive has not been reported in the literature previously. The present study revealed that RDW levels were higher in hypertensive patients with $\mathrm{AF}$ than that those without AF. Incidence of hypertension is high in the general population. Developing atrial fibrillation in this patient may poorly affect prognosis of the patient. An increased RDW level in the patient with hypertension may alert physician on developing or presence of atrial fibrillation.

\section{Conclusion}

RDW levels were higher in hypertensive patients with AF than that those without AF. An increased RDW level in the patient with hypertension may alert physician on developing or presence of atrial fibrillation.

\section{Limitations}

The main limitation of our study was the small sample size. A small sample size can result in a low statistical power for equivalency testing, leading to false-negative results. Second, because of the retrospective nature of data collection, echocardiographic parameters were not obtained concomitantly with blood sampling. Also, we were unable to evaluate some factors, such as Vitamin B12, ferritin that have been effected to the RDW, because data on these variables were not collected and we cannot apply our results for general population due to the broad exclusion criteria.

\section{Author contributions}

Sar1kaya S conceived and designed the study and was responsible for the acquisition of data. Sahin S conceived and designed the study and was responsible for the analysis and interpretation of data, manuscript draft and critical revision of the manuscript. Akyol L and Börekci $\mathrm{E}$ were responsible for the acquisition of data. Yilmaz YK conceived and designed the study and was responsible for the acquisition of data. Altunkas $F$ conceived and designed the study and was responsible for the analysis and interpretation of data and critical revision of the manuscript. Karaman $\mathrm{K}$ was responsible for manuscript draft and critical revision of the manuscript.

\section{References}

1. Chung MK, Foldvary-Schaefer N, Somers VK, Friedman PA, Wang PJ. 2004. Atrial fibrillation, sleep apnea and obesity. Nat Clin Pract Cardiovasc Med 1(1):56-59, quiz $51 \mathrm{p}$ following 59.

2. Keaney JF, Larson MG, Vasan RS, Wilson PWF, Lipinska I, Corey D, Massaro JM, Sutherland P, Vita JA, Benjamin EJ. 2003. Obesity and systemic oxidative stress - Clinical correlates of oxidative stress in the Framingham Study. Arterioscl Throm Vas 23(3):434-439.

3. Watanabe H, Tanabe N, Watanabe T, Darbar D, Roden DM, Sasaki S, Aizawa Y. 2008. Metabolic syndrome and risk of development of atrial fibrillation: the Niigata preventive medicine study. Circulation 117(10):12551260.

4. Benjamin EJ, Levy D, Vaziri SM, D'Agostino RB, Belanger AJ, Wolf PA. 1994. Independent risk factors for atrial fibrillation in a population-based cohort. The Framingham Heart Study. JAMA : the journal of the American Medical Association 271(11):840-844.

5. Psaty BM, Manolio TA, Kuller LH, Kronmal RA, Cushman M, Fried LP, White R, Furberg CD, Rautaharju PM. 1997. Incidence of and risk factors for atrial fibrillation in older adults. Circulation 96(7):2455-2461. 6. Krahn AD, Manfreda J, Tate RB, Mathewson FA, Cuddy TE. 1995. The natural history of atrial fibrillation: incidence, risk factors, and prognosis in the Manitoba Follow-Up Study. The American journal of medicine 98(5):476-484.

7. Patel P, Dokainish H, Tsai P, Lakkis N. 2010. Update on the Association of Inflammation and Atrial Fibrillation. Journal of cardiovascular electrophysiology 21(9):1064-1070.

8. Blake GJ, Rifai N, Buring JE, Ridker PM. 2003. Blood pressure, C-reactive protein, and risk of future cardiovascular events. Circulation 108(24):2993-2999.

9. Boos CJ, Lip GYH. 2006. Is hypertension an inflammatory process? Current Pharmaceutical Design 12(13):1623-1635.

10. Evans TC, Jehle D. 1991. The red blood cell distribution width. The Journal of emergency medicine 9 
Suppl 1:71-74.

11. Weiss G, Goodnough LT. 2005. Anemia of chronic disease. N Engl J Med 352(10):1011-1023.

12. Ferrucci L, Guralnik JM, Woodman RC, Bandinelli S, Lauretani F, Corsi AM, Chaves PH, Ershler WB, Longo DL. 2005. Proinflammatory state and circulating erythropoietin in persons with and without anemia. The American journal of medicine 118(11):1288.

13. Felker GM, Allen LA, Pocock SJ, Shaw LK, McMurray JJV, Pfeffer MA, Swedberg K, Wang DL, Yusuf S, Michelson EL, Granger CB. 2007. Red cell distribution width as a novel prognostic marker in heart failure - Data from the CHARM program and the Duke Databank. Journal of the American College of Cardiology 50(1):40-47.

14. Wang YL, Hua Q, Bai CR, Tang Q. 2011. Relationship between Red Cell Distribution Width and Shortterm Outcomes in Acute Coronary Syndrome in a Chinese Population. Internal Med 50(24):2941-2945.

15. Tonelli M, Sacks F, Arnold M, Moye L, Davis B, Pfeffer M, Tria CRE. 2008. Relation between red blood cell distribution width and cardiovascular event rate in people with coronary disease. Circulation 117(2):163168.

16. Ani C, Ovbiagele B. 2009. Elevated red blood cell distribution width predicts mortality in persons with known stroke. J Neurol Sci 277(1-2):103-108.

17. Kalay N, Aytekin M, Kaya MG, Ozbek K, Karayakali M, Sogut E, Altunkas F, Ozturk A, Koc F. 2011. The relationship between inflammation and slow coronary flow: increased red cell distribution width and serum uric acid levels. Turk Kardiyoloji Dernegi arsivi : Turk Kardiyoloji Derneginin yayin organidir 39(6):463-468.

18. Ghaffari S. 2008. Oxidative stress in the regulation of normal and neoplastic hematopoiesis. Antioxid Redox Sign 10(11):1923-1940.

19. Agarwal S. 2012. Red cell distribution width, inflammatory markers and cardiorespiratory fitness: Results from the National Health and Nutrition Examination Survey. Indian heart journal 64(4):380-387.

20. Wen Y. 2010. High red blood cell distribution width is closely associated with risk of carotid artery atherosclerosis in patients with hypertension. Experimental and clinical cardiology 15(3):37-40.

21. Vaziri SM, Larson MG, Benjamin EJ, Levy D. 1994. Echocardiographic Predictors of Nonrheumatic AtrialFibrillation - the Framingham-Heart-Study. Circulation 89(2):724-730.

22. Abhayaratna WP, Barnes ME, Cha S, Bailey KR, Mi- yasaka Y, Carlson LA, Abhayaratna K, Seward JB, Tsang TS. 2005. Prediction of cardiovascular outcomes with left atrial size: Is volume superior to area or diameter? Circulation 112(17):U398-U398.

23. Frustaci A, Chimenti C, Bellocci F, Morgante E, Russo MA, Maseri A. 1997. Histological substrate of atrial biopsies in patients with lone atrial fibrillation. Circulation 96(4):1180-1184.

24. Lo B, Fijnheer R, Nierich AP, Bruins P, Kalkman CJ. 2005. C-reactive protein is a risk indicator for atrial fibrillation after myocardial revascularization. Annals of Thoracic Surgery 79(5):1530-1535.

25. Perlstein TS, Weuve J, Pfeffer MA, Beckman JA. 2009. Red blood cell distribution width and mortality risk in a community-based prospective cohort. Arch Intern Med 169(6):588-594.

26. van Kimmenade RR, Mohammed AA, Uthamalingam S, van der Meer P, Felker GM, Januzzi JL, Jr. 2010. Red blood cell distribution width and 1-year mortality in acute heart failure. Eur J Heart Fail 12(2):129-136.

27. Dabbah S, Hammerman H, Markiewicz W, Aronson D. 2010. Relation Between Red Cell Distribution Width and Clinical Outcomes After Acute Myocardial Infarction. American Journal of Cardiology 105(3):312-317.

28. Pfister R, Diedrichs H, Schiedermair A, Rosenkranz S, Hellmich M, Erdmann E, Schneider CA. 2008. Prognostic impact of NT-proBNP and renal function in comparison to contemporary multi-marker risk scores in heart failure patients. Eur J Heart Fail 10(3):315320.

29. Dickstein K, Cohen-Solal A, Filippatos G, McMurray JJ, Ponikowski P, Poole-Wilson PA, Stromberg A, van Veldhuisen DJ, Atar D, Hoes AW, Keren A, Mebazaa A, Nieminen M, Priori SG, Swedberg K, Guidelines ESCCfP. 2008. ESC guidelines for the diagnosis and treatment of acute and chronic heart failure 2008: the Task Force for the diagnosis and treatment of acute and chronic heart failure 2008 of the European Society of Cardiology. Developed in collaboration with the Heart Failure Association of the ESC (HFA) and endorsed by the European Society of Intensive Care Medicine (ESICM). Eur J Heart Fail 10(10):933-989.

30. Tanindi A, Topal FE, Topal F, Celik B. 2012. Red cell distribution width in patients with prehypertension and hypertension. Blood pressure 21(3):177-181.

31. Ozcan F, Turak O, Durak A, Isleyen A, Ucar F, Ginis Z, Ucar F, Basar FN, Aydogdu S. 2013. Red cell distribution width and inflammation in patients with nondipper hypertension. Blood pressure 22(2):80-85. 